\title{
Optical Properties of $\mathrm{Ta}_{2} \mathrm{O}_{5} / \mathrm{SiO}_{2}$ Antireflection Coating System
}

\author{
Shaoni Sun ${ }^{1, a}$, Liyang Xie ${ }^{1, b}$, Yichen Zhang ${ }^{1, c}$, Ying Huang ${ }^{1, d}$
}

${ }^{1}$ School of Mechanical Engineering \& Automation, Northeastern University, Shenyang, Liaoning, China, 110004

ashnisun@me.neu.edu.cn, 'liyangxie@mail.neu.edu.cn, 'zyc@china.com, dyinghuang@mail.neu.edu.cn

Keywords: $\mathrm{Ta}_{2} \mathrm{O}_{5} / \mathrm{SiO}_{2}$ multi-layer, Antireflection coating, Optical properties, Technical study

\begin{abstract}
The $\mathrm{Ta}_{2} \mathrm{O}_{5} / \mathrm{SiO}_{2}$ multi-layer Antireflection coating is prepared on $\mathrm{K} 9$ glass by $\mathrm{RF}$ magnetron sputtering technology in the experiment. The growth parameters are changed to get multi-layer Antireflection film with good optical properties. In the technical research, the influence of various growth parameters, including working pressure, oxygen content, substrate temperature, etc., on the optical properties and structures of the coatings are studied. Optical properties and morphological features such as surface, structure are investigated by UV-VIS spectrophotometer and AFM, respectively. The detecting results further verify the important influences of proper growth parameters on optical properties of antireflection coating.
\end{abstract}

\section{Introduction}

Antireflection coating is most widely used optical coating, which can be used on camera lens, telescope, microscope and rangefinder etc.. Almost all the optical instruments use Antireflection coating for its improvement on the transmittance or image quality. The preparation technology of coating greatly influences its ultimate performance, especially for optical coating that needs precision processes [1]. How to well control process parameters is an important problem for the preparation of optical coating.

The research is based on the pre-design of the coating system, in which it is assumed that material refractive index is constant, and the coating thickness is determined according to this assumption. In fact, in order to obtain design results of multilayer coating system in the experiment, the premise is that required refractive index of each used coating material can be precisely determined, which puts forward an important issue for coating process: when the coating materials are chosen, the process parameters must maintain steady to ensure stable and repeated refractive index of coating material[ $2,3,4,5]$.

\section{Equipment device and preparation technologies}

The preparations of $\mathrm{SiO}_{2}$ and $\mathrm{Ta}_{2} \mathrm{O}_{5}$ coatings are carried on FJL560CIl ultra-high vacuum magnetron sputtering combined with ion beam coating machine, as shown in Fig.1.

After $\mathrm{K} 9$ glass substrate is cleaned, $\mathrm{SiO}_{2}$ and $\mathrm{Ta}_{2} \mathrm{O}_{5}$ coatings are prepared using $\mathrm{O}_{2}$ (purity 99.99\%) as reactive gas and $\operatorname{Ar}$ (purity $99.99 \%$ ) as working gas by RF magnetron sputtering, and the deposition rate of single-layer film is determined through the research of process parameters. It's not so easy to get $\mathrm{Ta}_{2} \mathrm{O}_{5}$ coating of high density, high quality and excellent optical properties on technology. The research for preparation and performance of $\mathrm{Ta}_{2} \mathrm{O}_{5}$ coating have made a lot in international, while domestic studies on this issue are rarely seen. 
Through the research of various deposition parameters, such as working pressure, oxygen content and substrate temperature, and so on, the properties closely related to Antireflection coating optical performance, including refractive index, structure and surface morphology are obtained. Based on the technology research, $\mathrm{Ta}_{2} \mathrm{O}_{5} / \mathrm{SiO}_{2}$ multi-layer Antireflection coating with excellent optical properties on $\mathrm{K} 9$ optical glass is gained finally.

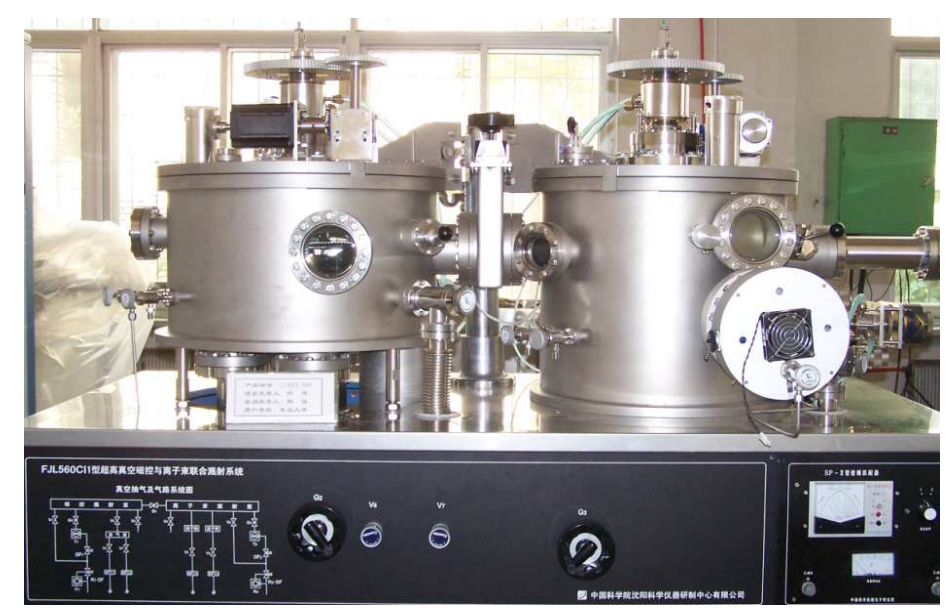

Fig. 1. FJL560CI1 ultra high vacuum magnetron sputtering combined with ion beam coating machine

\section{Experiment results and analysis}

Influence of working pressure on coating performance. During the experiment processing, working pressure is changed to investigate its influence on film structure and optical constant. The preparation parameters of $\mathrm{SiO}_{2}$ coating are as followed: target-substrate distance of $65 \mathrm{~mm}$, sputtering power of $100 \mathrm{~W}$ and oxygen content of $20 \%$, that of $\mathrm{Ta}_{2} \mathrm{O}_{5}$ coating are: target-substrate distance of $85 \mathrm{~mm}$, sputtering power of $100 \mathrm{~W}$ and oxygen content of $100 \%$. The relation curve of working pressure and index of refraction for $\mathrm{SiO}_{2}$ coating is shown in Fig.2, and that of $\mathrm{Ta}_{2} \mathrm{O}_{5}$ coating is shown in Fig.3.

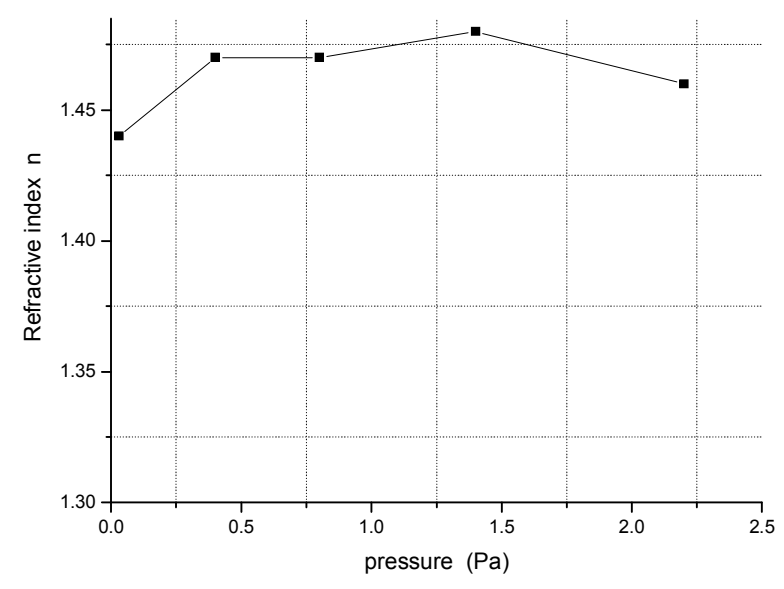

Fig. 2. Refractive index of $\mathrm{SiO}_{2}$ deposited deposited at different pressure

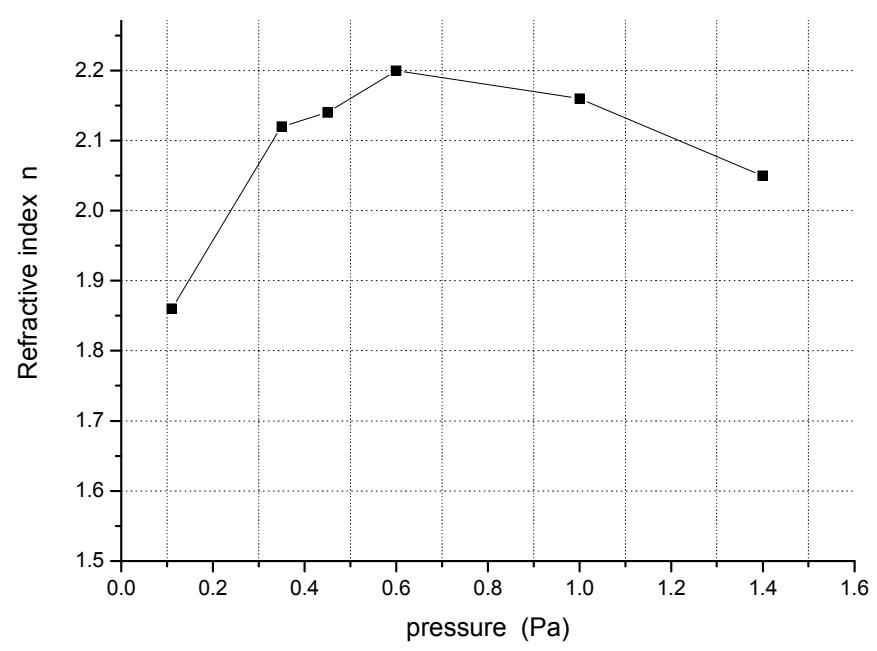

Fig. 3. Refractive index of $\mathrm{Ta}_{2} \mathrm{O}_{5}$ at different pressure

It can be seen that refractive index of $\mathrm{SiO}_{2}$ film firstly increases and then decreases when the working pressure increases from $0.03 \mathrm{~Pa}$ to $2.2 \mathrm{~Pa}$. The difference between maximum value and minimum one of refractive index is only 0.04 . When the coating is deposited at $0.03 \mathrm{~Pa}$, its 
refractive index is low because of the low deposition rate which leads to loose structure. Refractive index decreases while working pressure rises to $1.4 \mathrm{~Pa}$, which can be explained that excess gas molecules in vacuum chamber lead to the scattering of target particles and low deposition rate, so the coating is not dense enough and the refractive index decreases as a result.

The changing trend of $\mathrm{Ta}_{2} \mathrm{O}_{5}$ film's refractive index with the change of working pressure is roughly the same with $\mathrm{SiO}_{2}$. As shown in Fig.3, when working pressure is lower, the reaction of tantalum atoms is not sufficient, the deposition rate is low and the produced oxide is not dense enough, so the refractive index is low. When the working pressure rises to $0.4 \mathrm{~Pa}$, the deposition rate is appropriate for getting high quality coating, and the transmittance is the highest.

Table 1 Refractive index of $\mathrm{SiO}_{2}$ coating at different deposition conditions

\begin{tabular}{cccccc}
\hline $\begin{array}{c}\text { Sampl } \\
\mathrm{e}\end{array}$ & Pressure[Pa] & $\begin{array}{c}\text { Target-substrate } \\
\text { distance[mm] }\end{array}$ & $\mathrm{O}_{2}$ content[\%] & Power[W] & $\begin{array}{c}\text { Refractive } \\
\text { index }\end{array}$ \\
\hline 1 & 0.4 & 65 & 0 & 100 & 2.14 \\
2 & 0.4 & 65 & 5 & 100 & 1.680 \\
3 & 0.4 & 65 & 15.0 & 100 & 1.460 \\
4 & 0.4 & 65 & 24.0 & 100 & 1.440 \\
5 & 0.4 & 65 & 32.1 & 100 & 1.450 \\
\hline
\end{tabular}

Influence of $\mathrm{O}_{2}$ content on coating performance. Different refractive index of $\mathrm{SiO}_{2}$ coating is prepared at different $\mathrm{O}_{2}$ content, as shown in table 1 . When oxygen content reaches $13 \%$, the refractive index of $\mathrm{SiO}_{2}$ coating is approach to 1.46. While the oxygen content continues to increase, refractive index becomes stable, as shown in Fig.4.

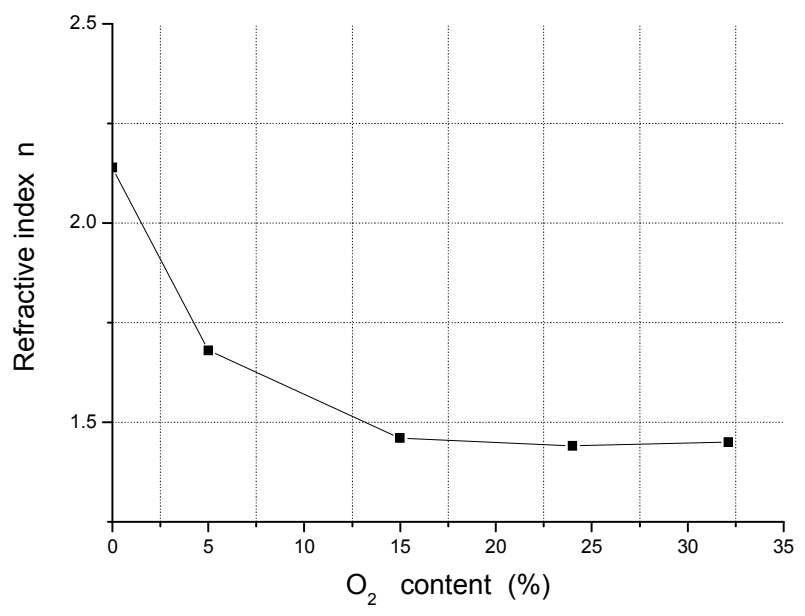

Fig. 4. Refractive index of $\mathrm{SiO}_{2}$ coating versus $\mathrm{O}_{2}$ content

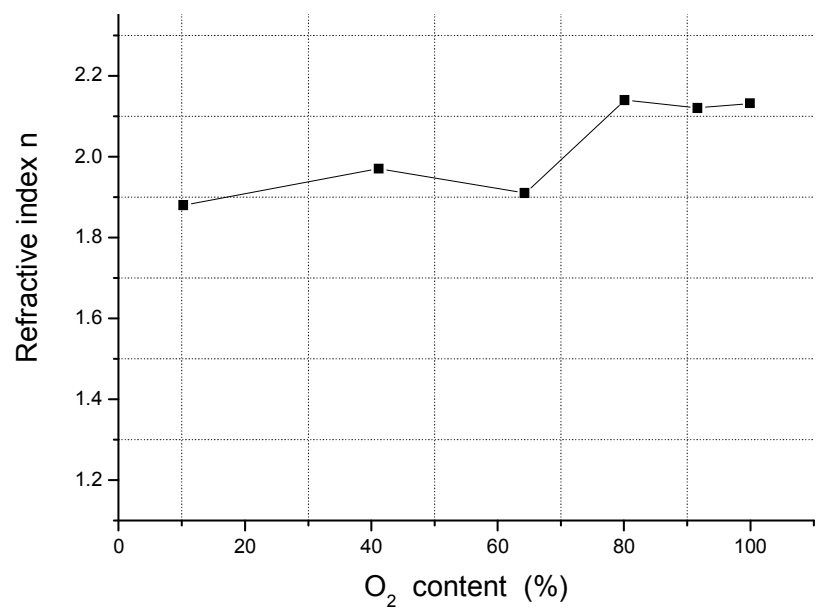

Fig. 5. Refractive index of $\mathrm{Ta}_{2} \mathrm{O}_{5}$ coating versus $\mathrm{O}_{2}$ content

$\mathrm{Ta}_{2} \mathrm{O}_{5}$ film tends to produce oxygen vacancies, so it's necessary to improve the oxygen content in reactive gases. Deposition process parameters of $\mathrm{Ta}_{2} \mathrm{O}_{5}$ film is shown in table 2 .

The change of refractive index with oxygen content for $\mathrm{Ta}_{2} \mathrm{O}_{5}$ film is shown in Fig.5. When oxygen content is less than $10 \% \sim 40 \%$, the refractive index is smaller; when oxygen content increases to $60 \% \sim 80 \%$, tantalum oxide film with higher oxygen content is prone to produce; and when oxygen content reaches $80 \% \sim 100 \%$, the film has shown high transparency, and the refractive index tends to be stable. 
Table 2 Deposition parameters of $\mathrm{Ta}_{2} \mathrm{O}_{5}$ coating

\begin{tabular}{ccccc}
\hline Sample & Pressure[Pa] & $\begin{array}{c}\text { Target-substrate } \\
\text { distance[mm] }\end{array}$ & $\mathrm{O}_{2}$ content[\%] & Power[W] \\
\hline 1 & 0.4 & 85 & 10.24 & 70 \\
2 & 0.4 & 85 & 41.20 & 70 \\
3 & 0.4 & 85 & 64.31 & 70 \\
4 & 0.4 & 85 & 80.14 & 70 \\
5 & 0.4 & 85 & 91.66 & 70 \\
6 & 0.4 & 85 & 100.00 & 70 \\
\hline
\end{tabular}

\section{Influence of substrate temperature on coating performance.}

Influence of substrate temperature on transmittance of film. The transmittances of films deposited at different substrate temperature are detected, as shown in Fig.6. When the substrates is heated to $300^{\circ} \mathrm{C}$, the maximum transmittance of $\mathrm{SiO}_{2}$ film increases, and also dose the difference between maximum transmittance and minimum one, which shows that the refractive index of $\mathrm{SiO}_{2}$ film increases.

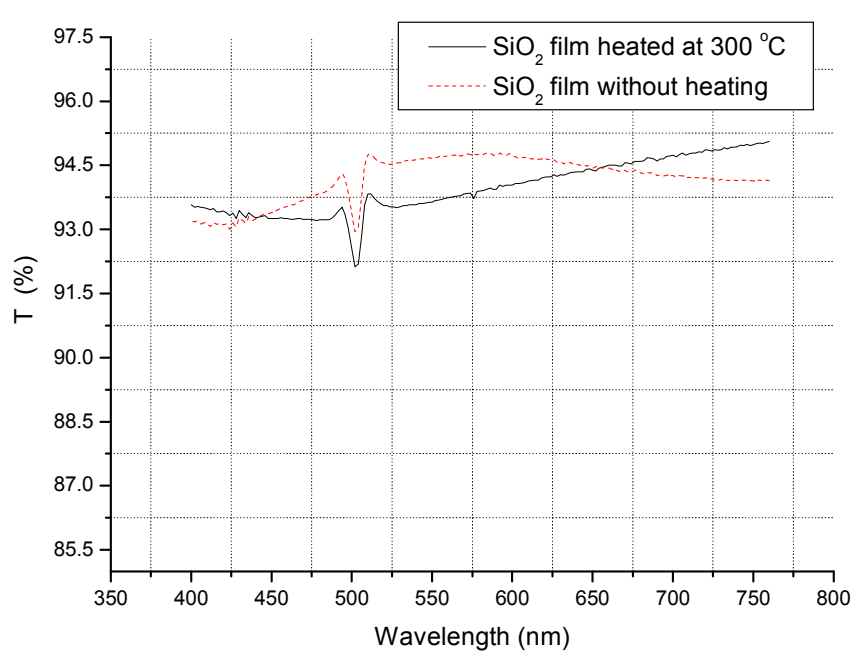

(a) Transmittance of $\mathrm{SiO}_{2}$ coating

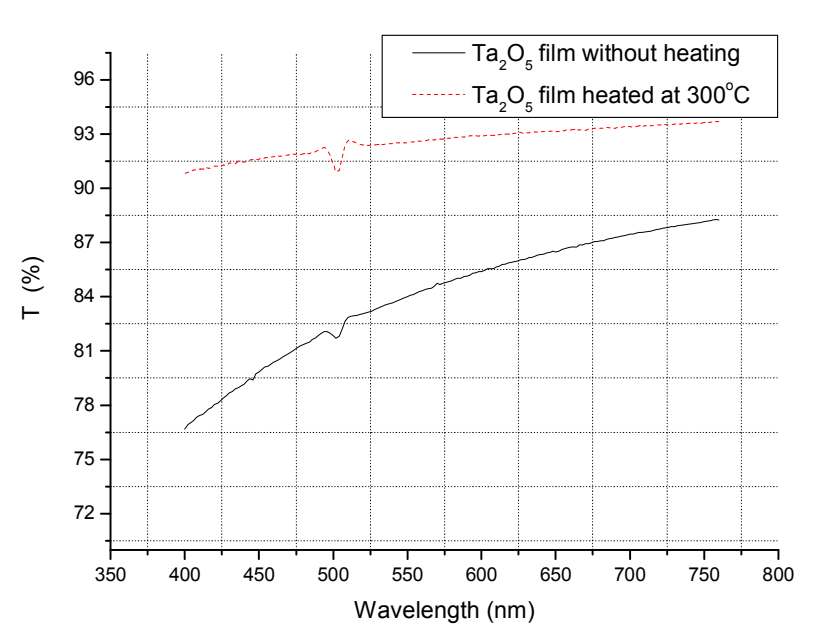

(b) Transmittance of $\mathrm{Ta}_{2} \mathrm{O}_{5}$ coating

Fig. 6. Transmittances of coatings deposited at different temperature

Transmittance of $\mathrm{Ta}_{2} \mathrm{O}_{5}$ film changes a lot with the increase of substrate temperature, as shown in Fig. 6 (b). It can be seen that substrate temperature greatly influences transmittance of $\mathrm{Ta}_{2} \mathrm{O}_{5}$ film in visible band, while the transmittance of not heated sample is $14 \%$ lower than that of sample heated to $300^{\circ} \mathrm{C}$ in band of purple light.

AFM morphological features analysis on samples at different substrate temperature. The $\mathrm{SiO}_{2}$ coatings prepared at different substrate temperatures are detected by AFM, as shown in Fig.7 (a). When the sample is not heated, the surface structure of film shows different microscopic lightness and shades. The uneven surface structure scatters the light so that the transmittance of film is influenced. When the sample is heated to $300{ }^{\circ} \mathrm{C}$, surface structure of film looks smoother and has fewer defects than film whose substrate is not heated, as shown in Fig.7 (b).

The analysis results show that, density of film increases with the increase of substrate temperature obviously, then the refractive index increases as a result. Substrate temperature is an important factor affecting the refractive index, so it has great significance to control substrate temperature for improving of film's density and refractive index. 


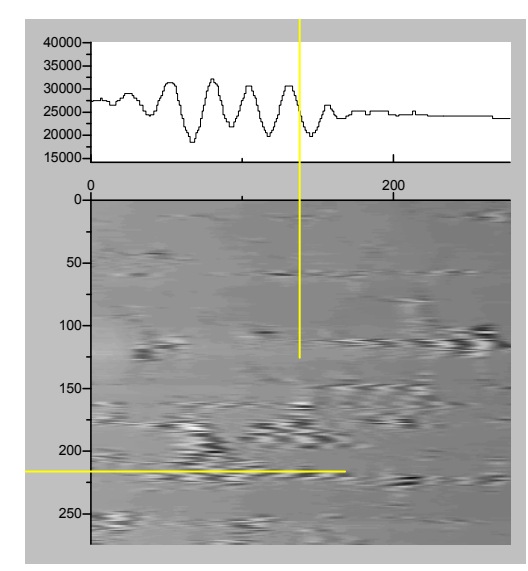

(a) sample unheated

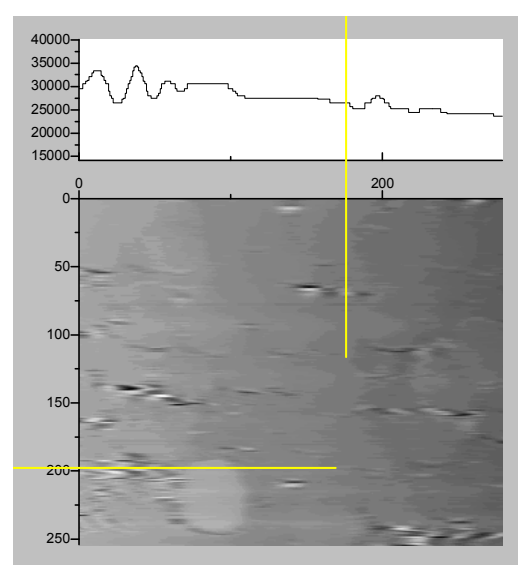

(b) sample heated to $300{ }^{\circ} \mathrm{C}$

Fig. 7. AFM images of $\mathrm{SiO}_{2}$ film deposited at different temperature

\section{Conclusions}

Through technical research, it is found that technology parameters including working pressure, $\mathrm{O}_{2}$ content and substrate temperature have much important influences on coating's optical properties.

Refractive indexes of $\mathrm{SiO}_{2}$ and $\mathrm{Ta}_{2} \mathrm{O}_{5}$ coatings show the same changing trend with the change of working pressure. When the working pressure rises to $2.2 \mathrm{~Pa}$, the deposition rate of $\mathrm{SiO}_{2}$ coating is appropriate for getting high transmittance coating, while the suitable working pressure for $\mathrm{Ta}_{2} \mathrm{O}_{5}$ coating is only $0.4 \mathrm{~Pa}$.

$\mathrm{O}_{2}$ content greatly affects the refractive index of film. Deposited $\mathrm{SiO}_{2}$ film will meet the design requirement when $\mathrm{O}_{2}$ content is higher than $13 \%$; while $\mathrm{O}_{2}$ content in $\mathrm{Ta}_{2} \mathrm{O}_{5}$ film growth should be over $80 \%$.

Substrate temperature has much important influence on film's optical properties. With the rise of substrate temperature, the surface of coating becomes more smoother and having fewer defects, and the coating's density also increases, so that the refractive index increases correspondingly.

\section{References}

[1] N.I. Klyuia, V.G. Litovchenkoa, A.G. Rozhina, Silicon solar cells with antireflection diamond-like carbon and silicon carbide films, Solar Energy Materials \& Solar Cells. 72(2002) 597-603.

[2] M.C. Ferrara, D. Altamura, M. Schioppa, Growth, characterization and optical properties of nanocrystalline gadolinia thin films prepared by sol-gel dip coating, Journal of Physics D: Applied Physics. 41(2008) 225408(9pp)

[3] W.H. Yang, G.B. Li, D.X. Wu, Design and Analysis of Anti-Reflection Coating for Solar Cells, Journal of Shanghai University (Natural Science Edition)., 10(2004) 39-42.

[4] J.H. Sun, B. Zhang, Y. Xu, et al. Preparation and Optical Properties of $\mathrm{SiO}_{2} \mathrm{AR}$ coating, Optical Technique. 2(2000)104-106.

[5] X. Zhang, L.X. Hang, Preparation of anti-reflection films by PECVD technology, Optical Technique. 37(2011)97-100. 